\title{
Adaptation of the RepTrak Model to Measure the Reputation of Higher Education Institutions
}

\author{
Yaroslava Bratus * [0000-0001-9199-2858], Mykola Sydorov [0000-0002-5333-8393]
}

Taras Shevchenko National University of Kyiv, Ukraine

*bratus.yara@gmail.com

\begin{abstract}
Increasingly, the main criterion for the classification and grading of higher education institutions is reputation, that in contrast to other criteria - the number of citations, the percentage of employed graduates, lecturing staff and international cooperation - is understudied. In Ukraine, there is no information on such studies for higher education institutions in open access. Therefore, this research project aims to clarify the features of data and other possible models and the possibilities of their adaptation, modification and use to measure academic reputation. Based on the executed comparative theoretical analysis, one reputation model, the RepTrak, was selected for further adaptation and testing, due to its more extensive structure that measures the emotional and rational components of reputation. The model authored by Charles Fombrun and Enrique Carreras has been chosen since it is widely used to study organizations of various kinds, including educational ones. The use of adapted tools was carried out by conducting online surveys of various groups related to the higher education institutions: students, enrollees, employers. The obtained sociological information is aimed at confirming its validity and reliability through analysis in the program $\mathrm{R}$. In addition to adapting the reputation model, an attempt was made to theoretically modify existing models to more sociological ones. The limitations of this research project include studying of a limited number of reputation models and choosing only one of them, although adaption and comparison of several models in the future is possible that will allow to illustrate the advantages and disadvantages of measuring corporate reputation more accurately and comprehensively.
\end{abstract}

Keywords: reputation, academic reputation, models of reputation measurement, trust index, reputation factors, emotional-rational structure.

\section{INTRODUCTION}

The object of research is the reputation of higher education institutions, i.e. a certain evaluative perception within a specific interest group or stakeholders. The study of reputation in domestic research is carried out mostly using the models of Reputation Quotient [1] and [2]. In this case, reputation is a theoretical construct, i.e. a set of factors and indicators for its measurement depends on a particular historical and cultural or social context. Different channels of self-presentation are used to build a reputation [3-5]. This approach applies not only to organizations but also to separate social institutions or individuals. An integral concept for reputation is awareness. Reputation can only be measured towards a group of stakeholders who have a sufficient level of awareness and can provide reliable information [6]

For a long time, the biggest problem in approaching the study of the reputation of an individual or a whole community or company was the fragmentary nature of the theoretical foundation, due to which the concept was often considered irrational and immeasurable. In addition, the difficulty was also in assimilation of the concepts of "image" and "reputation", that are, in fact, different, since the image is a tool of reputation management, it is a general idea existing about the person, organization, etc. and reputation is an intangible asset, a cumulative opinion of the public or individuals about the object. Image is a sign of quality and has the ability to influence the degree of loyalty and decisionmaking rules of stakeholders [7]. In the field of higher education, research is carried out on both image and reputation, but as distinct characteristics, so they involve creation of various methodological approaches that will be aimed at identifying specific features of the studied phenomena [8]. Reputation is largely the result of consistent behavior, while image can be more easily managed and changed through communication campaigns. In this article, the focus is shifted to the first concept and its study, because for higher education 
institutions it contains a certain empirical development and directly or indirectly answers the questions that should be considered in this article.

Research on the reputation of higher education institutions is a topical issue, as changes have taken place in recent years that affect the education system as a whole. These include:

1. The decision-making system in universities currently has a smaller share of professors and a larger share of administration, who in their end should have more specialized knowledge on the educational process, administrative and reputation management [9-11].

2. Higher education institutions now meet the needs of students and teachers better than before, which is an additional incentive for competition between different universities in trying to offer better services $[12,13]$. This does not abolish the basic functions of higher education institutions, but at the same time creates new ones that require not only the improvement of institutions' services, but also the management of reputation among well-defined groups of stakeholders. Reputation gains in some studies correlate with students' desire to enter the university $[14,15]$.

3. Higher education institutions are becoming more "socialized" due to the spread of social media, greater involvement in social activities (expressing a clear position on pressing and problematic issues, participation in charity events, etc.) $[12,13]$. Given the greater social integration of higher education institutions, there is a need to clearly define the attributes and factors by which it will be possible to measure reputation, create an effective strategy to control and improve it [16].

The purpose of this article is involving theoretical and practical knowledge for the concept of "corporate reputation" in the study of the reputation of higher education institutions and adapting of the RepTrak model as one of the most common for commercial and noncommercial organizations.

\section{RESEARCH METHODOLOGY. THE CONCEPT OF "CORPORATE REPUTATION" AND A MODEL FOR MEASURING IT}

The definition and concept of corporate reputation proposed by $\mathrm{C}$. Fombrun is chosen as the basis, which assumes that: "Corporate reputation is a collective assessment of a company's attractiveness to a specific group of stakeholders relative to a reference group of companies with which the company competes for resources" [17]. The key ideas that characterize Fombrun's approach are:
1. Every organization has one reputation, but its level depends on the specific target audience. For example, for consumers and non-consumers reputation will be measured by the same logic, but the results will be different. The same goes for other groups of stakeholders.

2. Corporate reputation is a concept that is considered through comparison, because to evaluate any organization we must focus on a particular construct, that is in most cases other organizations. For the most part, comparisons are made within the same sector of companies. Measuring reputation separately for a higher education institution, for example, gives researchers an understanding of the level of key performance indicators that help to build a reputation strategy, but when compared to others, how competitive they are in relation to other institutions [18].

3. A reputation considered between organizations is a source of competition which has its advantages and disadvantages. Being a company in conditions of fierce competition due to the level of reputation can impose certain pressure not only on the company itself, but also on consumers of goods or services in this field [19].

The following definitions should be preserved in the structure of corporate reputation when considering it in the field of higher education:

- Reputation as a collective assessment;

- Reputation as the embodiment of the company's attractiveness;

- Reputation as a characteristic is relevant to a certain set of stakeholders;

- Reputation depending on the reference group can have significant differences [20].

Adherence to such a set of characteristics of the structure of corporate reputation will not only provide the most generalized understanding of this concept, but also contribute to a better understanding of its differences with the concepts of "image", "vision", "identity" and so on.

The use of the concept of corporate reputation avoids uncertainty as to how its value differs from the academic reputation used in the ranking of higher education institutions. QS World University Rankings is in particular, where the weight of reputation is $40 \%$, but its operationalization differs from the one we have outlined above [21]. In the future, it is necessary to define the ratio, common and distinctive features of these concepts, and now we turn to the RepTrak model [2] as a vivid illustrative example of how the concept of corporate reputation proposed by Charles Fombrun is implemented on an empirical level. 
The RepTrak model was first introduced in Madrid in 2005 , and a presentation took place in 2006, after the model was refined [22]. The indicator of perception and emotional attractiveness in this model is RepTrak Pulse or trust index with dimension from 0 to 100 points and is an average of four emotional indicators: trust, respect, admiration and good feeling. It can be used to determine the level of trust of the representatives of a certain target group to the organization.

Using the concept of trust as an index based on the values of four different integral indicators, and not through a single question, solves the problem of differences in the interpretation of the concept of "reputation" by representatives of one or different groups of stakeholders. In addition, the appeal to emotional characteristics successfully explains one of the dimensions of higher education institutions, which refers to the fact that universities are carriers of moral values, i.e. an illustration of their perception as "compassionate, flexible and honest'" [23]. The model also takes into account the cultural aspect of the macroenvironment, which directly affects the representation of reputation by representatives of different reference groups. It can be reflected in the symbols or be associated with a macroinstitutional context, systemic cultural features at the level of a country [24].

The rational component of the RepTrak model includes seven factors [25] consists of a set of attributive values that outline in more detail all levels of the organization (Table 1):

Table 1. Factors and attributes RepTrak

\begin{tabular}{|c|c|}
\hline Factors & Attributes \\
\hline \multirow{4}{*}{ Products and services } & 1. Offers high quality products and services \\
\hline & 2. Offers goods and services that have good value for money \\
\hline & 3. Stands for its products and services \\
\hline & 4. Meets customer needs \\
\hline \multirow{3}{*}{ Innovations } & 5. This is an innovative company \\
\hline & 6. As a rule, the company is the first to enter the market of new goods and services \\
\hline & 7. Quickly adapts to change \\
\hline \multirow{3}{*}{ Workplace } & 8. Rewards its employees fairly \\
\hline & 9. Demonstrates concern for the health and well-being of its employees \\
\hline & 10. Offers equal opportunities in the workplace \\
\hline \multirow{3}{*}{ Governance } & 11. Open and transparent about how the company works \\
\hline & 12. Ethical behavior \\
\hline & 13. Fair in its activities \\
\hline \multirow{3}{*}{ Citizenship } & 14. Acts responsibly to protect the environment \\
\hline & 15. Supports good intentions \\
\hline & 16. Positively affects society \\
\hline \multirow{4}{*}{ Leadership } & 17. Has a strong and attractive leader \\
\hline & 18. Has a clear vision of its future \\
\hline & 19. This is a well-organized company \\
\hline & 20. Has great managers \\
\hline \multirow{3}{*}{ Performance } & 21. This is a profitable company \\
\hline & 22. Gives better financial results than expected \\
\hline & 23. Shows high prospects for future growth \\
\hline
\end{tabular}

A separate element of this model is also the definition of supportive behavior, i.e. the extent to which people are willing to cooperate, recommend, express positive opinions, trust the organization's products and services no matter what [17]. This category is extremely important for measuring at the level of the trust index and factors/attributes, because in this way we find out how high the level of support is and who can be potential promoters of the faculty, institute or university [26]. 


\section{RESEARCH RESULTS. ADAPTATION OF THE REPTRAK MODEL TO MEASURE THE REPUTATION OF HIGHER EDUCATION INSTITUTIONS}

Higher education institutions around the world and in Ukraine in particular are subject to organizational requirements previously set by American universities. It cannot be said that this is a prerequisite for activity, but in order to get into the international rankings for the quality of educational services, to be able to collaborate with others or participate in various research projects on a global scale, the institutions must meet certain requirements and standards [27]. Universities will respond differently to such conditions. They may meet them in a number of ways: resist, transform, and adapt these requirements to different national and local contexts. Given the above, higher education institutions are now more socially integrated, needing to improve not only for local stakeholder groups, but also to meet the norms and standards shared by the international community [28]. In this case, the measurement and management of reputation are important both to influence the minds of enrollees, students, professors, employers to cooperate with higher education institutions, and to improve the situation in the international market of higher education.

The problem that has been identified during the detailed analysis of the current situation of academic ranking and reputation is the lack of adapted tools for the study of the reputation of higher education institutions. To solve this problem, we propose to consider the adaptation of the RepTrak model on the example of a sociological study, which aims to measure the reputation of the Faculty of Sociology of Taras Shevchenko National University of Kyiv for three categories of stakeholders: students of the Faculty of Sociology, students of other faculties and employers. This practical survey has an exploratory strategic plan, so we did not define hypotheses for it, and formulated conclusions in accordance with the objectives. As a result of this study, we have formulated detailed recommendations on the possibility of further improvement and use of the adapted RepTrak methodology to measure the reputation not only of the Faculty of Sociology of Taras Shevchenko National University, but also of other higher education institutions.

175 students and 25 employers took part in testing of the adapted methodology. The survey was conducted online by sending a link to the electronic survey to personal e-mail or by sharing it through social medias.

The basic structure of the RepTrak model, namely the trust index, factors and attributes, is chosen as a basis for creation of the adapted technique. All attributes have been adapted for higher education institutions that have specific features in comparison with commercial organizations for which this model had been created. The attributes were formulated on the basis of the analysis of documents related to the quality of educational services in Ukraine, educational programs of the Faculty of Sociology, and program documents. In addition, after the first stage of formulation of variables, a pretest of tools was conducted, as a result of which the formulation of those attributes that were difficult to interpret and inappropriate for this study, was revised and changed.

\section{DISCUSSION OF RESULTS}

The adapted RepTrak model for measuring the reputation of higher education institutions (Faculty of Sociology, Taras Shevchenko National University of Kyiv) has the following structure (Table 2).

For a more thorough study of the adapted model for measuring reputation an open-ended question was added where respondents could leave comments on how well they understood the questions or whether they had any difficulties in interpretation, and so on. This need arose because the concept of reputation is quite difficult to understand and everyone has their own understanding of what it means, so to avoid collisions with misunderstandings in the interpretation of key categories by the researcher and the respondent, additional questions were added.

\section{CONCLUSIONS}

After the analysis of the adapted model approbation, certain advantages and disadvantages of this model have been identified; this will encourage further development and further validation of the methodology for measuring the reputation of higher education institutions, which will help to measure the trust index among target audiences and to identify the affecting factors and how they affect this indicator. All this is possible with the principle underlying the RepTrak model that stands for the division of factors into emotional and rational spheres, studying the coefficient of influence on the trust index and types of supportive behavior of individual attributes or factors, which helps to build an effective strategy to improve the reputation of higher education institutions and contributes to increasing satisfaction with the level of educational services.

The main directions for further research on this methodology are involvement of variables that provide an opportunity to measure the level of awareness on an institution of higher education among different groups of stakeholders in the adapted model; revision of the list of factors and attributes in accordance with the new requirements for the quality of educational services and international standards in the field of higher education; taking into account a cultural indicator that has a significant impact on the stakeholders' perception of the reputation of a higher education institution. The study 
described above is the first step towards achieving this goal.

Examining the reputation of higher education institutions through the key categories of the concept of "corporate reputation" proposed by Charles Formbrun, provides an opportunity to describe this phenomenon in more detail than it would be possible through the concept of "academic reputation", which appears in various rankings of higher education and tends to be a more subjective category, or the usual indicator of the quality of educational services. It can also be an effective solution to the lack of publicly available tools for measuring the reputation of higher education institutions by using developments for corporate reputation models and adapting them to the specifics of higher education and universities as specific organizations providing educational services to students, professors, investors or employers, and act as an important institution for the formation, transmission or cultivation of certain national or global values, traditions, cultural characteristics, i.e. act not only as an important channel for social mobility, but also for the education of intellectual, political or cultural elite.

Table 2. The structure of the adapted RepTrak model

\begin{tabular}{|c|c|}
\hline Factors & Attributes \\
\hline \multirow{4}{*}{$\begin{array}{l}\text { Products and } \\
\text { services }\end{array}$} & Provides an opportunity to obtain quality education; \\
\hline & Provides an opportunity to gain knowledge that is important for future professional activities; \\
\hline & $\begin{array}{l}\text { Satisfies the needs of students in professional growth (invited lecturers, internships, elective } \\
\text { courses, etc.); }\end{array}$ \\
\hline & Provides knowledge that is competitive with the faculties of sociology of other universities. \\
\hline \multirow[t]{3}{*}{ Innovations } & This is an innovative company \\
\hline & One of the first to introduce new disciplines, courses that are relevant; \\
\hline & Introduces innovative forms of education to improve the level of education. \\
\hline \multirow[t]{4}{*}{ Workplace } & The faculty has a system of incentives for students; \\
\hline & Offers quality learning conditions (classrooms, library, logistics, etc.); \\
\hline & The organization of the educational process is at a high level (schedule, tests and exams, etc.); \\
\hline & Organization of leisure practices for students (interesting conferences, various events). \\
\hline \multirow[t]{4}{*}{ Governance } & The faculty adheres to ethical norms; \\
\hline & $\begin{array}{l}\text { Faculty members and staff are fair to all students, regardless of gender, religion, race, etc. } \\
\text { characteristics; }\end{array}$ \\
\hline & The activities of the faculty are transparent and open to the public; \\
\hline & The rights and freedoms of students and employees are not violated at the faculty. \\
\hline \multirow[t]{4}{*}{ Citizenship } & Joins in solving current problems of society; \\
\hline & Adheres to the code of academic integrity; \\
\hline & Conducts educational activities on specific aspects in various spheres of life; \\
\hline & Participates in charitable and community projects. \\
\hline \multirow[t]{3}{*}{ Leadership } & The head of the faculty is an excellent leader; \\
\hline & Teachers are highly qualified and encourage students to study professional disciplines; \\
\hline & Has a clear development strategy. \\
\hline \multirow[t]{3}{*}{ Performance } & Is a leader in the field of sociological education; \\
\hline & $\begin{array}{l}\text { Provides highly qualified specialists to work in sociological, marketing, analytical, etc. } \\
\text { companies; }\end{array}$ \\
\hline & Has excellent prospects for development and expansion (new specializations for example). \\
\hline
\end{tabular}

\section{REFERENCES}

[1] Fombrun, C. Gardberg, N. and Sever, J. (2000), "The reputation quotient: amulti-stakeholder measure of corporate reputation", Journal of Brand Management, vol. 7 (4), pp. 241-255.

[2] The RepTrak Company (2021), Retrieved 10th of October 2021, available at: https://www.reptrak.com/
[3] Mouna El, Marrakchi Hicham, Bensaid and Mostafa, Bellafkih (2017), "E-Reputation Prediction Model in Online Social Networks", International Journal of Intelligent Systems and Applications, vol. 9, no. 11, pp.17-25. DOI: $10.5815 /$ ijisa.2017.11.03 
[4] Mohammed, Azza and Sofiane, Boukli Hacene (2017), "An Enhanced Reputation-based for Detecting Misbehaving Nodes in MANET", International Journal of Wireless and Microwave Technologies, vol. 7, no. 4, pp.28-37. DOI: $10.5815 /$ ijwmt.2017.04.03

[5] Emad Elabd (2015), "A Dynamic ReputationBased Approach for Web Services Discovery", International Journal of Information Technology and Computer Science, vol. 7, no. 8, pp.31-36. DOI: $10.5815 /$ ijitcs.2015.08.05

[6] Brewer, A. and Zhao, J. (2010), "The impact of a pathway college on reputation and brand awareness for its affiliated university in Sydney", International Journal of Educational Management, vol. 24 (1) pp. 34-47, DOI: $10.1108 / 09513541011013033$

[7] Fornell, C. Rust, R.T. and Dekimpe, M.G. (2010), "The effect of customer satisfaction on consumer spending growth", Journal of Marketing Research, vol. 47 (1), pp. 28-35. DOI: 10.1509/jmkr.47.1.28

[8] Del-Castillo-Feito, C. Blanco-González, A. and González-Vázquez, E. (2019), “The relationship between image and reputation in the Spanish public university", European Research on Management and Business Economics, vol. 25 (2), pp. 87-92, DOI: 10.1016/j.iedeen.2019.01.001

[9] Bleiklie, I. and Michelsen, S. (2013), "Comparing HE Policies in European Structures and Reform Outputs in Eight Countries", Higher Education, vol. 65 (1), pp. 113-133.

[10] Enders, J. de Boer, H. and Meyer, E. (2013), "Regulatory Autonomy and Performance. The Reform of Higher Education Revisited", Higher Education, vol. 65(5), pp. 5-23.

[11] Ginsberg, B. (2013), The fall of the faculty: the rise of the all-administrative university and why it matters, Oxford University Press, Oxford.

[12] Ramirez, F. Meyer, J.W. and Lerch, J. (2016), World Society and the Globalization of Educational Policy. Handbook on Global Policy and Policy Making in Education (pp. 43-63), Malden, MA: Wiley Blackwell.

[13] Ramirez, F.O. and Christensen, T. (2013), "The Formalization of the University: Rules, Roots, and Routes", Higher Education, vol. 65 (6), pp. 695708 .
[14] Sudiharto, Rosita and Anggraini, Irwansyah (2019), "The Effect of Reputation and Academic Service Quality Toward Student Satisfaction. Advances in Social Science", Education and Humanities Research, vol. 423. 2nd International Media Conference 2019 (IMC 2019), p. 437- 446. DOI: 10.2991/assehr.k.200325.034

[15] Nuriah Vani Ramdhiani and Rahma Wahdiniwaty (2018), "The Effect of The College Reputation on Student's Decision Making to Choose It/ Advances in Social Science", Education and Humanities Research, vol. 225. International Conference on Business, Economic, Social Sciences and Humanities (ICOBEST 2018), p. 515-517. DOI: $10.2991 /$ icobest-18.2018.102

[16] Sufrin Hannan (2020), "Building a Brand in Higher Education: A Review of the Literature on Higher Education Institutions Brand Management", Advances in Social Science, Education and Humanities Research, vol. 566, Proceedings of the 5th Asian Education Symposium 2020 (AES 2020), p. 50-54. DOI:10.2991/assehr.k.210715.010

[17] Fombrun, C. (2007), Essentials of Corporate Communication, Routledge Taylor \& Francis Group, London.

[18] Carreras, E. Alloza, A. and Carreras, A. (2013), Corporate Reputation, LID Published Ltd, London.

[19] Hemsley-Brown, J. and et al. (2016), "Exploring brand identity, meaning, image, and reputation (BIMIR) in higher education: A special section", Journal of Business Research, vol. 69, pp. 30193022. DOI: 10.1016/j.jbusres.2016.01.016.

[20] Ovrutsky, A. (2016), "Reputation. Reputational discourse. Reputational", Psychologist, vol. 5, pp. 10-18.

[21] QS World University Rankings ${ }^{\circledR}(2021)$, Retrieved 25th of May 2021, available at https://www.topuniversities.com/qs-worlduniversity-rankings/methodology.

[22] Sarstedt, M. (2013), "Measuring reputation in global markets - A comparison of reputation measures", Journal of World Business, vol. 48, pp. 329-340.

[23] Carpenter, D. and Krause, G.A. (2012), "Reputation and Public Administration", Public Administration Review, vo. 72 (1), pp. 26-32.

[24] Fombrun, C. (2018), Reputation. Realizing value from the corporate image, LID Published Ltd, London. 
[25] Fombrun, C. Ponzi, L. and Newburry, W. (2015), "Stakeholder Tracking and Analysis: The RepTrak ${ }^{\circledR}$ System for Measuring Corporate Reputation", Corporate Reputation Review, vol. 18, pp. 3-24. DOI:10.1057/crr.2014.21

[26] Gurieva, S. Pochebut, L. Chiker, V. and Yanicheva, T. (2019), "Social Representations about Reputation as the Company's Social Capital", Advances in Social Science, Education and Humanities Research, 1st International Scientific Practical Conference "The Individual and Society in the Modern Geopolitical Environment" (ISMGE 2019), vol. 331, p 267-271. DOI: 10.2991/ismge19.2019.51
[27] Sydorov, M. and Salnikova, S. (2021), "SERVQUAL Model in HEI Monitoring Survey as a Part of Quality Assurance Policy", Advances in Economics, Business and Management Research, Proceedings of the International Conference on Economics, Law and Education Research (ELER 2021), vol. 170, pp. 204-209. DOI: 10.2991/aebmr.k.210320.036

[28] Christensen, T. and Gornitzka, A. (2017), "Reputation management in complex environments - A comparative study of university organizations", Higher Education Policy, vol. 30, pp. 123-140. 